\title{
Educación y resistencia: la creación de un campo epistémico por la intelectualidad afrocolombiana*
}

DOI: https://doi.org/10.18046/recs.i3o.3843

\author{
Education and Resistance: An Epistemic Field Created \\ by the Afro-Colombian Intelligentsia
}

\author{
Jorge Enrique García-Rincón ${ }^{* *}$ \\ Universidad del Cauca (Popayán, Colombia)
}

\footnotetext{
* Gran parte de este artículo está basado en las conclusiones de la tesis doctoral Por fuera de la casa del amo, presentada en la Universidad de Nariño, en 2016. Artículo de reflexión recibido el 15.02.2019 y aceptado el 06.01.202O.

** Doctor en Ciencias de la Educación y magíster en Orientación Educativa y Desarrollo Humano por la Universidad de Nariño (Colombia). Licenciado en Filosofía de la Universidad del Valle (Colombia). Correo electrónico: jegar2013@ hotmail.com ORCID: https://orcid.org/oooo-0oo3-4682-2125
} 


\section{Cómo citar/How to cite}

García-Rincón, Jorge Enrique (2020). Educación y resistencia: la creación de un campo epistémico por la intelectualidad afrocolombiana. Revista CS, 30, 17-45. https://doi.org/10.18046/recs.i30.3843 


\section{Resumen}

El artículo versa sobre las concepciones de la educación construidas por intelectuales negros independientes y por el movimiento social afrocolombiano en confrontación con el proyecto educativo estatal. Es posible constatar la emergencia de un pensamiento político-pedagógico en perspectiva del pueblo negro en distintos lugares del país. No obstante, en el artículo se retoman experiencias muy concretas de gestión intelectual dirigidas por pensadores como Diego Luis Córdoba, Manuel Zapata Olivella, Rogerio Velásquez y Amir Smith Córdoba, entre otros. Al mismo tiempo, se analiza la forma como los intelectuales de las iniciativas de educación propia en los territorios de las comunidades negras han aportado en la continuidad del discurso crítico educativo iniciado por los pensadores desde las primeras décadas del siglo XX. Además, se contemplan algunas de las ideas de maestros y maestras, líderes comunitarios que confrontaron al Estado en la práctica misma de la pedagogía para la identidad política.

\section{PALABRAS CLAVE:}

intelectualidad negra, humanismo afrodiaspórico, suficiencia pragmática y creativa, epistemología propia, cultura negra

The article deals with the conceptions of education constructed by independent black intellectuals and by the Afro-Colombian social movement in contrast with the state educational project. It is possible to see the emergence of political-pedagogical thinking from the perspective of the black people in different parts of the country. However, the article takes up very concrete experiences of intellectual management led by thinkers such as Diego Luis Córdoba, Manuel Zapata Olivella, Rogerio Velásquez, and Amir Smith Córdoba, among others. At the same time, it analyzes how the intellectuals of own education initiatives in the territories of black communities have contributed to the continuity of the critical discourse on education initiated by thinkers since the first decades of the 2oth century. It also considers some ideas of the teachers, community leaders who confronted the State in the very practice of pedagogy for the political identity.

\section{KEYWORDS:}

Black Intelligentsia, Afro-diasporic Humanism, Pragmatic and Creative Sufficiency, Own Epistemology, Black Culture 



\section{Introducción}

Ubicar los puntos clave con los que se desarrolla el pensamiento crítico afrocolombiano en el siglo XX implica la identificación de hitos fundacionales del discurso educativo de los intelectuales negros consagrados en profesiones liberales que cuestionaron el estamento oficial de enseñanza. Esos elementos clave representan un conjunto de ideas críticas que integran el campo epistémico, en cuya construcción, consolidación y socialización también han participado maestros y maestras, dirigentes comunitarios, investigadores, activistas, mujeres, jóvenes y mayores de las comunidades negras colombianas en su condición de intelectuales.

En los años ochenta, los jóvenes bachilleres de Villa Paz, en Jamundí, Valle, organizaron puchas para pensar el proyecto educativo comunitario. La pucha es una forma organizativa endógena de los negros del Norte del Cauca; es una reunión con comida que, de acuerdo con Obirne Carabalí (comunicación personal, 30.10.2014), debe hacerse preferiblemente con gallina o pato robado; allí los hombres cocinan para las mujeres, se hace de noche y se constituye en escenario de diálogo sobre las problemáticas que los aquejan. La pucha es un desafío a las formas organizativas establecidas y un ejercicio de autonomía, muy probablemente heredado de los "arrochelamientos" de la época colonial. "Arrochelarse" era una forma de cuestionar la legitimidad del ordenamiento social colonial y, de hecho, poner en evidencia otras formas de vivir, organizarse y existir (Herrera, 2010). Los negros arrochelados eran huidos de la esclavitud de las haciendas y de los enclaves mineros; querían asegurar una vida distinta por fuera de las reglas del régimen colonial. Cimarrones, huidos o "arrochelados" fueron categorías que respondían, ni más ni menos, al proyecto histórico del negro en las Américas. Los arrochelados eran símbolo de libertad y constructores de experiencias de convivencia social, que dan cuenta de otras concepciones de estar en el mundo.

Lo mismo que los cimarrones en la Colonia, algunos intelectuales negros del siglo XX en Colombia, en un acto de insumisión, comprendieron la necesidad de arrochelarse, es decir, alejarse, salirse de los márgenes del discurso oficial de educación, así como de la estructura académica occidentalizada, para construir las bases del pensamiento educativo afrocolombiano.

Las luchas de los intelectuales negros, así como las manifestaciones del movimiento social afrocolombiano en torno a la defensa de una educación que dignificase la vida de sus poblaciones, no pueden considerarse más que como continuidad del proyecto libertario del negro en Colombia. El campo epistémico, llamado aquí pensamiento educativo afrocolombiano, ha trasegado por caminos distintos a los de la institucionalidad y más concretamente se le ha opuesto en forma beligerante. Este asunto, es 
decir, la construcción de un ideal educativo del que depende la creación de cultura propia, solo fue posible por fuera de la casa del $\mathrm{amo}^{1}$; valga afirmar que el amo colonial se prolongó en la historia en el entramado y la rigidez institucional, que ha impedido la manifestación abierta del negro en la sociedad colombiana y latinoamericana.

En este artículo se esbozarán los elementos que fundan el pensamiento educativo afrocolombiano y los principales conceptos derivados de las reflexiones de los intelectuales negros y de los proyectos de educación construidos autónomamente dentro de las comunidades.

Además, se abordarán ideas de Manuel Zapata-Olivella, Rogerio Velásquez, Obirne Carabalí, Emiro Lucumí, Rubiela Mideros, Genara Arboleda, Mary Lucia Hurtado, Amir Smith Córdoba, entre otros. Todos ellos, desde los debates académicos hasta la animación de los procesos educativos propios en los territorios, han contribuido en forma consciente y permanente en la construcción de un campo epistémico pedagógico y educativo en Colombia.

\section{Concepciones, enfoques y pilares de la educación afrocolombiana}

La historia de la libertad será el primer elemento que fundamenta la educación en la comunidad afrocolombiana y, como se ha analizado en Rogerio Velásquez (2010), la libertad es posible entenderla, en el siglo XX, como comprensión crítica de la historicidad. En términos de Paulo Freire (1967), sería la conciencia crítica capaz de superar el determinismo histórico implicado en la conciencia ingenua. No obstante, en el caso específico de los intelectuales negros del siglo XX, la libertad pasa, también, por una necesaria introspección, que le permitirá al negro un encuentro consigo mismo, que es, en todo caso, el encuentro con sus hermanos de raza, de infortunio y de historia y anterior a cualquier otro encuentro con sectores sociales diferentes, tal como lo ha explicado Amir Smith Córdoba (1980); pero, aún más, la libertad como comprensión crítica de la historia servirá para elevar la conciencia acerca del conflicto social y político del que ha dependido la marginalidad del negro en Colombia y en América; aunque la libertad solo es posible cuando, a partir de la conciencia crítica, se interviene en la historia con fines de trasformación.

En este sentido, no podría existir un proyecto educativo, en la perspectiva de los pueblos negros, sin una crítica frontal al capitalismo colonial, racista, moderno y deshumanizador, causante, tanto en el pasado como en el presente, de la subalter-

1. Por fuera de la casa del amo es el título con que se publicó la investigación de la cual deriva este artículo. 
nización social, económica y política del negro. La educación liberadora se piensa, en este discurso, como aquella que rompe con las cadenas mentales, procura la descolonización de las prácticas de vida apegadas al canon occidental y prepara al sujeto para un cuestionamiento del orden establecido.

No se trata aquí de la libertad como un discurso neutral y despolitizado, tampoco de la libertad que profesaba el padre de Manuel Zapata-Olivella, esto es, de corte individual y sujeta a la promesa de la modernidad europea, que asocia la libertad con Ilustración. Zapata-Olivella (1990a) observa el asunto con más detenimiento; en su libro iLevántate mulato!, cuenta sobre la familia de los Zambrano, negros puros e insumisos de Cartagena, que se rebelan frente a todo institucionalismo. Estos hombres y mujeres, fuertes, prácticos y prevenidos contra las insinuaciones a hacer parte del estamento, se niegan rotundamente a asistir a la escuela y se resisten, en general, a la participación institucional. Esta es la clave para comprender, en el principio de la libertad, el componente vital de la acción, que se mantiene alejado de cualquier posibilidad de sujeción. La escuela, en esta perspectiva, es leída como instrumento para la sujeción.

Si bien la libertad es, también, conocimiento de la historia de la libertad, en la condición de los hombres y mujeres negros, que han vivido en medio de sociedades abiertamente racistas, esto no significa un asunto especulativo. Por el contrario, la educación liberadora, discutida en el Quinto Encuentro de Pastoral Afroamericana (EPA) (Diócesis de Quibdó, 1991), así como los desarrollos del pensamiento de Amir Smith Córdoba (1980), han indicado que la libertad implica el conocimiento, la apropiación y la trasformación de la cultura negra hacia una construcción política, por lo cual es lícito afirmar que la libertad se asocia con la combinación de todos los factores de la identidad, que implica, además de los procesos organizativos, la reafirmación cultural de los sujetos.

Otro aspecto que funda las reflexiones sobre la educación afrocolombiana es el anhelo de maestros, líderes sociales e intelectuales de romper los esquemas totalmente cerrados de la escuela oficial, a partir de la puesta en marcha de lo que se ha llamado la diversidad epistémica (Castro-Gómez; Grosfoguel, 2007). En efecto, de lo dicho por estos autores, podemos inferir que la escuela, la universidad y, en general, la educación occidentalizada responden a la modernidad europea, en términos de proyecto colonial civilizatorio. Desde este punto de vista, la autoridad del conocimiento se ubica en los países del norte, de Europa, desde donde se imponen al resto del mundo no europeo; la escuela oficial, fundada sobre esta matriz epistémica, es unidireccional y excluyente.

La descolonización de la escuela pasa por un diálogo interepistémico; es decir, por una suerte de interculturalidad crítica, que no solo promueva la universalidad 
inventada del conocimiento europeo, sino también el pluriverso de las ideas; lo contrario sería reproducir el sistema racista en la escuela colombiana. Justamente, la diversidad epistémica es la apuesta de los pensadores negros del siglo XX, así como de los líderes de las experiencias educativas del movimiento social, que coinciden en la idea de que no basta luchar solo por una educación para los negros, sino, en general, para el conjunto de los explotados y sujetos reprimidos en el ámbito del capitalismo.

Diego Luis Córdoba (1934) engloba este pensamiento en el concepto resignificado de proletariado, que no solamente incluye a los asalariados descritos en la teoría marxista, sino también a los pueblos víctimas del colonialismo religioso, epistemológico, cultural y económico, en medio del cual también se halla la gente de su raza.

Para el profesor Emiro Lucumí, de la experiencia educativa de Villa Paz, se trata de concebir a la escuela como aquella institución que posibilita y sostiene la polifonía de saberes de la humanidad, y no los de una parte de ella. Por otro lado, el maestro Manuel Zapata-Olivella (1990a) introduce el concepto de mestizaje como escenario de confluencia de los sujetos marginales y racializados. El mestizaje es la posibilidad de nuevos proyectos humanísticos y lugar para construir una interculturalidad radical. Todas estas manifestaciones de solidaridad en favor del otro, que sufre similares condiciones de subalternización que el negro, es lo que se ha planteado, en otro texto (García-Rincón, 2011), como la ética de la diversidad. Asiste el convencimiento de que la inclusión de la diversidad epistémica en la escuela, con la que se enfrentará el racismo y la política de la exclusión, debe acompañarse de una ética que valore y respete los saberes de cada pueblo o cultura. Como reservorio de solidaridad humana, en estos asuntos las comunidades negras tienen un terreno histórico ganado.

En consonancia con lo anterior, al revisar los textos y discursos de los pensadores negros del siglo XX en Colombia, se encuentra la postura según la cual la educación debe responder a dos elementos centrales: por un lado, una mirada hacia adentro, que concibe los procesos pedagógicos desde las entrañas de la comunidad, con la participación de sus miembros en el diseño y ejecución de la propuesta educativa; este aspecto se puede testimoniar con los aportes de Rogerio Velásquez (2010) que, en su acercamiento a la noción de educación propia, derivada de las sugerencias de resignificación del proyecto educativo del Atrato medio en el Chocó, sostiene que los métodos y contenidos escolares deben ajustarse a las realidades propias de la cotidianidad cultural de las comunidades. Desde luego, esta no es una propuesta simple, pues se trata de un acto vanguardista que, en los años sesenta, era imposible pensarlo desde los pueblos negros en Colombia; es una contribución al debate sobre la autonomía territorial, y una de las primeras sugerencias de insumisión epistémica, que se implementaría al interior de la escuela oficial en el país. 
Por otro lado, una mirada hacia afuera, en la que la educación se caracterizaría por la presencia de la diversidad epistémica, en cuyo caso el aporte de los afrocolombianos a la identidad nacional se proyectaría en la socialización de la cultura negra como parte de los contenidos escolares que han de impartirse a los estudiantes colombianos de todos los niveles. En este punto, es preciso destacar el discurso de Manuel Zapata-Olivella (1988) en el evento de Cali de $1977^{2}$, cuando, en calidad de delegado de Colombia, destacó la necesidad de incluir la cultura negra en el pénsum académico oficial de los países de América. Este posicionamiento es posible considerarlo como precursor del proyecto de Cátedra de Estudios Afrocolombianos, desarrollado en los años noventa del siglo XX.

Esto quiere decir que la mirada hacia adentro, es decir, la educación propia, servirá para sostener los pilares de una episteme afrocolombiana presente en la integridad e intimidad de sus valores y su cultura, mientras que la mirada hacia afuera, representada en la Cátedra de Cultura Negra, no solo pretende visibilizar los aportes afro en la definición de la identidad colombiana, sino también generar una tensión política y un debate académico sobre los modos de relacionamiento entre el modelo de sociedad nacional y la presencia de la diáspora africana en Colombia.

Los discursos educativos afrocolombianos del siglo XX pueden considerarse como parte de una tensión, en la que se enfrentan una racionalidad técnica y una racionalidad cultural y política; es decir, las políticas estatales que representa el Ministerio de Educación en Colombia responden a directivas supranacionales, conectadas con los intereses del capitalismo global desde las primeras décadas del siglo XX; ya se trate de asuntos meramente pedagógicos o de administración de la educación, las corporaciones económicas norteamericanas terminan por imponer normas, ajustes, restricciones de todo tipo, para lograr que prevalezcan los sistemas de evaluación exacerbadamente técnicos, con el propósito de mantener el control sobre el Sistema Educativo Nacional.

En materia pedagógica, la racionalidad técnica tyleriana se quiso imponer en Colombia desde los años setenta, después de que el país había recibido diversas misiones europeas, desde los comienzos de la República hasta mediados del siglo $X X$. Desde este punto de vista, en Colombia, la pedagogía, y en general la educación, es un discurso foráneo, regido por las leyes, directivas e intereses económicos y geopolíticos de Europa y Norteamérica. En cambio, la racionalidad cultural y política con la que los intelectuales negros desarrollan sus ideas en educación se centra en la recuperación de una episteme sistemáticamente excluida y en la creación de una 
conciencia nacional que fuese capaz de comprender y compartir en la diversidad racial y cultural. Esta racionalidad cultural y política es, también, la apuesta por un humanismo afrodiaspórico, que confronta el racismo y toda acción deshumanizadora presente en el sistema público de educación.

A propósito del humanismo a fro, se podría decir que las estrategias que utilizaron los africanos en América como respuesta a la esclavización fueron sencillamente respuestas humanas frente a condiciones de adversidad y sujeción. El argumento que justificaba la esclavitud del negro, por parte de los europeos, se centraba en una supuesta ausencia de moralidad, de pensamiento, de espiritualidad, en pocas palabras, de ausencia de humanidad. Aunque los europeos sabían que sus argumentos eran falaces, se inventaron para los africanos y su diáspora en América un absurdo proceso de "humanización", por la vía de la esclavización; esto es, había que esclavizar a los negros para redimirlos del pecado, es decir, de la culpa de su infidelidad al cristianismo, proceso que hoy se conoce como las tecnologías de la salvación (Chaves-Maldonado, 2009). Estas tecnologías cambiaron el plano de realidad de los africanos y sus descendientes, los despersonalizaron y deshumanizaron al extremo, como ha quedado claro en Los condenados de la tierra, de Fanon (1983).

Ante este escenario, por demás hostil, la diáspora africana se rebela, con acciones naturalmente humanas. En situación de exilio forzoso (Zapata, 1992), en condiciones de objeto de animadversión, de esclavización, etc., los seres humanos buscan restituir su humanidad con acciones humanas. Al utilizar el mismo dispositivo mental con el que actuaron en su contra los opresores europeos, el negro reacciona, en el sentido en que la respuesta es una acción reflexionada o pensada, que ha podido suceder individual o colectivamente, pero siempre en la línea de una restitución ontológica. Esta respuesta es el verdadero humanismo afro; no es una respuesta instintiva, es el pensamiento afrodiaspórico que reacciona ante el proyecto del colonialismo europeo; en la medida en que se produce en condiciones excepcionales de sometimiento, este pensamiento se desarrolla con mayor amplitud. La mayor capacidad de pensar en contextos complejos de sujeción se ha denominado, en otro texto, elasticidad racional afrodiaspórica (García-Rincón, 2011). La categoría indica que las reacciones pueden ser diversas e insospechadas; se trata de inventar y de reinventar la restitución ontológica de la diáspora africana. En otros términos, la diáspora africana esclavizada o en condiciones de marginalidad de tipo colonial desarrolla un estado de inteligencia profunda, materializado en una simbiosis con el entorno natural y en una concepción de mundo relacional. Su cosmovisión garantiza el futuro a través de un pensamiento en movimiento que se distribuye en el tiempo usando el vehículo de la oralidad. Las nuevas generaciones cosecharan este pensamiento en acción bajo la figura de suficiencia pragmática. Esto significa que se ha acrecentado 
la capacidad de hacer, reaccionar, adaptarse, soportar, recrear, sostenerse, rebelarse y preservarse en medio de las adversidades. La suficiencia pragmática es también suficiencia creativa; alude entonces a la creatividad desbordante que construye vida colectiva y producción de cultura material a partir de los recursos disponibles y en uso de una memoria inteligente que crea y recrea nuevos mundos. No se trata, sin embargo, del pragmatismo utilitario e industrial norteamericano, todo lo contrario, la suficiencia pragmática y creativa en las poblaciones negras sometidas es la capacidad de transformar inteligentemente el entorno social que se presenta hostil, escaso y desajustado como escenario de vida humana. Al respecto, el sacerdote Bernardo Merizalde (1921), quien había descalificado a la gente negra del Pacífico, señalando una supuesta falta de inteligencia, dice que:

En la costa del Pacífico la poesía se manifiesta vigorosa con aquella enjundia y sabor que le da el alma popular. Esos negros, que moran como disgregados en un rincón de la tierra del resto de los hombres, que apacientan sus entendimientos en las obras de modernos versos iquién lo creyera! Son verdaderos poetas. (158)

También destaca el autor la forma como los negros del Pacífico pueden adecuarse a las reglas de la poesía a su modo o sencillamente ignorarlas en el propósito de lograr una expresión propia:

El romance, como adecuado para vaciar en el [sic] toda el alma, lo manejan los negros a su albedrio, sin doblegarse ante reglas cuya existencia ignoran, de donde se origina la mezcla de asonantes y consonantes o el uso exclusivo de los segundos, la falta de métrica muchas veces y la carencia de otras cosillas que los críticos anatematizan con justicia, pero que merecen indulgencia en el vulgo por lo que vale el fondo recio y pujante unas veces, jocoso otras, sencillo y tierno siempre [...] Hemos visto negros que sin saber leer ni escribir improvisaban largas composiciones y las conservaban en la memoria. (Merizalde, 1921: 160)

Por otra parte, lo racional, como elemento constitutivo de la especie humana, no surge con la filosofía de Platón, Descartes o Kant; es, ante todo, la marca característica y diferenciadora entre los humanos y otras especies vivas, razón por la cual, en el pensamiento educativo de los intelectuales afrocolombianos, aparece una reclamación explícita acerca de la humanidad del negro, reclamación que se traduce en una suerte de voluntad de ser; así lo ha dejado ver Amir Smith Córdoba (1980) cuando expone que:

Un hombre que ha vivido una cultura sistemáticamente avasallada debe aspirar antes que todo al encuentro consigo mismo; es decir, está bien que colabore y comparta 
con quienes así lo "deseen” o se predisponga a ello, pero denle una oportunidad, permítanle ser. $(73)$

Y, a renglón seguido, agrega: "Escúchenme, no quiero ni deseo seguir siendo en función de otro" (73).

En este pensamiento, se percibe la voluntad de ser como conciencia de la humanidad negada a la diáspora africana por parte de la episteme colonizadora europea, negación que Maldonado-Torres (2007) llama colonialidad del ser y es la razón por la que, al parafrasear a Grosfoguel (2012), el supuesto "ser" está en el norte y el supuesto "no ser" está en el sur.

La voluntad de ser afrodiaspórica no se deriva, como pudiera pensarse, de la voluntad de poder (Nietzsche, 200o), pues no se trata del deseo de ser más que el otro o que los otros; al contrario, es simplemente voluntad de ser en el sentido, ya expresado, de restitución ontológica del negro en cuanto víctima de un sistema deshumanizador. La voluntad de ser se expresa también, en el decir de Amir Smith Córdoba (1980: 30), cuando señala el deseo de hacer valer la importancia de ser negro, o cuando se refiere a que la necesidad de ser es el anhelo de vivir digna y humanamente; más aún, el autor refiere que, en el Comité de la Negritud, reunido en São Paulo, en 1965, ante la necesidad de evitar que al negro se lo siguiera definiendo por otros, a través de fábulas fantásticas, el evento adopta como premisa: "sé negro, negro, negro, maravillosamente negro" (1980: 98); sin embargo, el ser negro, esto es, la voluntad de ser, es algo que debe enseñarse. Ya que en la sociedad en la que se vive todos quieren ser blancos, ha dicho el autor, es bueno detenerse, para enseñarle al negro a que aprenda a ser negro (1980: 55). Esto indica que uno de los pilares del pensamiento educativo afrocolombiano se asocia indefectiblemente con la urgencia de trabajar pedagógicamente la identidad. Por lo tanto, ser negro es un asunto enseñable, esto es, competencia de la educación.

Uno de los aspectos más recurrentes en Amir Smith Córdoba (1980: 77), como pensador, y también en Jesús Lácides Mosquera (1975: 101), es su preocupación por el encuentro del negro consigo mismo, asunto que resulta muy importante para establecer la categoría de identidad política crítica, toda vez que el negro consigo mismo es el principio de la subjetividad colectiva; es decir, la voluntad de ser es voluntad de ser con todos.

En función de deconstruir las explicaciones acerca de la inferioridad del negro, los intelectuales afrocolombianos se han empeñado en mostrar que en la condición humana restituida se implica la capacidad de pensar. Al respecto, Miguel A. Caicedo-Mena (2011: 18) ha señalado que, en los tiempos del segregacionismo educativo en el Chocó, los aristócratas blancos aducían que los negros no tenían capacidad 
para el estudio; no obstante, quedó demostrado, de acuerdo con el autor, "que, una vez garantizada la educación secundaria para el pueblo, el noventa y seis por ciento de los negritos resultaron estudiosos e inteligentes".

En consecuencia, dado que el pensamiento es una de las condiciones que caracterizan lo humano, no se puede predicar como atributo de una parte de la humanidad y no de la otra. Este argumento permite afirmar que es, por lo menos, incoherente el que las universidades de hoy en América Latina sigan doblegadas a la matriz epistémica euronorteamericana y no hagan el intento de un acto creativo y autonómico, en términos de apostarle a la forja de un pensamiento más auténtico (García-Rincón, 2014).

La autenticidad, en el pensamiento de América, debe ser una mirada hacia adentro, donde se recuperasen las visiones de mundo de los directamente afectados por el proyecto colonial europeo; esto es, la necesidad de tomar como punto de partida las epistemologías subalternizadas de negros e indígenas, cuyos elementos centrales no se distancian entre sí; por el contrario, son parte de la matriz primigenia de las civilizaciones humanas, que Europa ha intentado desarticular desde el siglo XV, sin conseguirlo.

En el traslado forzoso y dramático de millones de africanos a las nuevas tierras conquistadas por Europa, fenómeno conocido como diáspora africana, se da comienzo a un proceso de tensión en larga duración, donde el proyecto de recuperación de la condición humana africana discute en forma permanente con el proyecto colonial racista que niega dicha humanidad. El proceso de reconstrucción epistémica, evidenciado en luchas cimarronas, en los discursos políticos, la literatura, las propuestas de educación alternativa, la poesía, las narrativas orales, etc., crea el corpus argumentativo que se puede denominar pensamiento afrodiaspórico. En realidad, visto de esta manera, se trata del humanismo afrodiaspórico, entendido como la construcción de concepciones edificantes y dignificantes sobre sí mismo. Estas concepciones de los miembros de la diáspora africana en América son anteriores al humanismo cartesiano, con el que Europa inaugura la racionalidad instrumental, que desemboca en el método experimental kantiano, y que, a su vez, se traduce como ciencia con pretensiones de universalidad.

En efecto, como lo ha explicado Dussel (1994), antes que el ego cogito está el ego conquiro, lo que permite afirmar que, al enfrentar al conquistador, al enviado de Dios, al blanco europeo, la diáspora africana en América se reconstruye permanentemente y se reencuentra consigo misma. En cambio, el humanismo y el racionalismo cartesiano son posteriores a las reacciones de África y su diáspora por la recuperación de su identidad humana, pisoteada por la invasión blanca europea. Conscientes de su invariable condición de hombres y mujeres pensantes, pertenecientes a las primeras 
sociedades humanas, los africanos en el exilio forzado van a insistir en la defensa de su humanidad, absurda e intencionalmente cuestionada por el afán de riquezas de los cristianocéntricos procedentes del territorio de la vieja Hispania. Como se verá enseguida, una vez consolidada la arrogancia de Europa, es decir, lo que Santiago Castro-Gómez (2010) llama "La hybris del punto cero", se van a sofisticar las formas de la negación al ampliar sus dominios al campo de la academia, escenario en el que quedará "científicamente" comprobada la inferioridad de las culturas y sociedades no europeas.

La concepción unívoca de las ciencias, el pensamiento, el arte, la cultura, desarrollada en el seno de la academia europea y reproducida en las universidades occidentalizadas de América y otras latitudes, ha creado una forma de imagen-espejo, donde debe reflejarse la humanidad entera. Se trata de una suerte de orden académico mundial, donde se concibe la idea de que no es posible producción alguna de conocimiento sin la aceptación o validación por parte de los centros científicos de Europa y Norteamérica. A esta concepción arrogante de la academia occidental y a la manera como impone reglas en el circuito centro-periferia se le ha denominado sujeción epistémica (García-Rincón, 2016).

La sujeción epistémica implica un sometimiento a los parámetros establecidos desde los centros de poder académico, a cuyos indicadores es necesario aplicar para que un tipo específico de conocimiento pudiera alcanzar el estatus cientifico. Las universidades de América, sometidas a estos códigos, desde los comienzos de la colonización, sirvieron no solo como escenario de formación de las elites dominantes, sino también, desde finales del siglo XIX, de miembros de la diáspora africana que, pese a las innumerables dificultades y específicamente a los dispositivos racistas existentes en su época, lograron el acceso a la educación superior (Flórez-Bolívar, 2009).

Los miembros de la población afro que, al final del siglo XIX y principios del XX, ingresaron a las universidades de Colombia fueron también víctimas de la sujeción epistémica. Manuel Zapata-Olivella (1990a) ha revelado que su padre, creyente ciego en las bondades del positivismo, no pudo ver el pensamiento que se ocultaba en las tradiciones culturales de su pueblo. Sin embargo, uno de los ejes centrales en este estudio es visibilizar el deslinde que hacen los intelectuales negros del siglo XX de la matriz epistémica occidental. Al pronunciar discursos educativos en favor de su gente, lograron establecer una fractura en los principios y fundamentos de la academia occidentalizada. A esta ruptura epistemológica, muy notoria en la mayoría de los pensadores estudiados, se le ha denominado insumisión epistémica (García-Rincón, 2016).

La insumisión epistémica es la rebeldía contra el canon académico occidental, pero, también, el desarrollo de la capacidad de confrontarlo, en el entendido de su 
pertenencia a la estructura de poder colonial. En la medida en que el pensamiento insumiso desobedece las reglas de lo académicamente establecido, no solo se ubica en el límite de esa forma de conocimiento, sino que además va configurando una postura crítica situada, constructora de conocimientos nuevos y distintos. Los pensadores negros insumisos, desobedientes y cimarrones, en uso de su esencia creadora, postularon, en el siglo XX, nuevas concepciones de la vida, de lo humano, de lo académico, de la cultura, de la sociedad y de la educación.

Al cuestionar las políticas estatales de educación, los intelectuales negros y las experiencias del movimiento social han enfrentado la voluntad de verdad, que, en términos de Foucault (2010), se refiere al poder institucional, cuya labor de exclusión ejerce sobre la sociedad distintas formas de presión y coacción. Desde esta orilla, la voluntad de verdad es la jerarquización del discurso, que distribuye su validez, con dependencia de su origen y su afiliación institucional. La verdad se deriva del poder de la institucionalidad y va en escala descendente hacia lo falso; es decir, aquello que, por fuera del poder, se considera locura. Contra esa voluntad de verdad, típica de los discursos oficiales que fijan las políticas públicas en educación, ha actuado, en forma insumisa, el pensamiento educativo afrocolombiano.

\section{La epistemología propia}

Además de lo expuesto, tres elementos claves se pueden observar en la forma como este pensamiento ha intervenido en el debate educativo nacional, oponiéndose a la voluntad de verdad estatal: la postulación de una epistemología de la educación afrocolombiana, el intento de cambiar los poderes de la escuela y la creación de símbolos culturales que actúan como narrativas cohesionadoras para el ejercicio de la unidad y la autonomía.

Cuatro de las experiencias educativas propias estudiadas (Casita de Niños, Gente Inquieta e Ineafro, en Buenaventura, y La Playa [Francisco Pizarro-Nariño]), desde los inicios, fundan su quehacer educativo y pedagógico en los saberes ancestrales de las comunidades; defienden y socializan las estrategias didácticas tradicionales, que vinculan valores, conocimientos y prácticas pertenecientes a la cosmovisión de los pueblos de ancestro africano. Su fe y su confianza en que la recuperación y registro de las construcciones sociales, espirituales y productivas de estas comunidades son vitales en los procesos de formación, ubican a los promotores de este enfoque en el sitial de los constructores de una epistemología "otra".

En términos pedagógicos, esta epistemología de la educación afrocolombiana desmonta la idea de la autoridad del maestro como única fuente de los saberes, con 
lo cual se opone, también, al enciclopedismo, llamado, en algunos ámbitos escolares, racionalismo académico, método conductista y memorístico, tradicional en la educación colombiana. La epistemología que estas experiencias proponen desde sus prácticas pedagógicas tiene como centro el saber de los mayores, así como su participación en los procesos y escenarios de aprendizaje comunitarios.

Como se ha planteado en otro texto (García-Rincón, 2011:214), cuando se habla de lo pedagógico, no solo se hace referencia a la teoría relacionada con cómo aprenden los niños y las niñas negras en una ciudad o región determinada, sino que se habla también de los métodos y prácticas de transmisión de los saberes inmersos en la cotidianidad del contexto cultural afrodiaspórico. Este aspecto pedagógico de la educación afro rechaza la tensión entre conocimiento universal y conocimiento local; la universalidad solo puede comprenderse si comporta la totalidad de los saberes de los seres humanos y no solamente su segmento occidental. En este caso, la mediación pedagógica consiste en posibilitar el conocimiento a partir de las prácticas, pensamiento y saberes culturales que se viven cotidianamente en una comunidad.

Del estudio de algunas experiencias educativas propias, se deduce que la epistemología de la educación afrocolombiana construye un lenguaje para señalar la existencia de un conocimiento, unas prácticas y un proyecto de convivencia humana, que se diferencia de otros proyectos sociales en el país. La utilización recurrente de las expresiones "lo nuestro", "lo propio", por parte de los maestros y líderes comunitarios del Pacífico sur, es una demostración de apego o arraigo a formas particulares de ser, saber y tener. En todo caso, un acto de validación de estos saberes en el seno mismo de la cultura y la comunidad está antecedido por la idea según la cual los saberes tradicionales de la comunidad deben pasar intactos al ámbito escolar.

Dos de las experiencias educativas estudiadas, Escuela La Playa (Francisco Pizarro, Nariño) y el Colegio Comunitario de Villa Paz (Jamundí, Valle), emprenden acciones, desde la cosmovisión y tradiciones culturales afro, para intentar un cambio en los poderes de la escuela presente en sus comunidades. En efecto, en estas experiencias, los promotores o dirigentes, tomados de la memoria ancestral, construyen el ideario de la educación por fuera de la escuela, para luego introducirse en ella con el propósito de debatir y trasformar la oferta de formación para la comunidad; se trata de una confrontación entre el derecho ancestral de las comunidades y la oferta oficial del Estado.

Así como la educación formal ha tenido el poder de menospreciar, humillar, racializar, inferiorizar al negro, se espera que con la inclusión de los saberes de los pueblos, sus valores y prácticas culturales, su espiritualidad y su pensamiento propio, se transformasen los poderes escolares peyorativos en otros de carácter humanístico, como la solidaridad, el respeto, la convivencia pacífica, la autogestión, la libertad 
política, la identidad, la dignidad humana, la autonomía territorial y la armonía con la naturaleza. Con ello, queda indicado que el propósito de la escuela, visto desde las comunidades negras, es difundir un pensamiento desesclavizador, que pueda confrontar en forma permanente y que pueda correr a la par con las nuevas estrategias de colonización en sus territorios. Al cambiar los poderes de la escuela, la primacía del discurso oficial desaparece y entra a prevalecer el discurso político, basado en los derechos y la autonomía de las comunidades.

En cuanto a los elementos cohesionadores para la unidad de la población afrocolombiana, Rogerio Velásquez (2010) ha dicho que los maestros deben ser capaces de crear símbolos culturales que sirvan como aglutinadores comunitarios, que representasen algo que la gente se interese en seguir. Algunos de estos símbolos se esbozaron en los textos de Miguel A. Caicedo-Mena (2011), Manuel Zapata-Olivella (1990b) y Amir Smith Córdoba (1980). Miguel A. Caicedo-Mena (2011) introduce la expresión cotidiana del Pacífico: "Su gente de uno", para indicar, en un nivel local o regional, un elemento clave del discurso que funciona como receptáculo de solidaridad y hermandad entre los negros. "Su gente de uno" es una expresión aglutinadora, porque sugiere identidad de pueblo, cohesión y autonomía. Como símbolo cultural, la aplicación de este dicho comunitario trasciende la esfera local y regional y se transforma en un elemento articulador de la población negra por fuera de sus territorios, pero se recurre a giros en el lenguaje, como "mi raza", "mi sangre", "mi paisano", "mi primo". Justamente el "paisanaje" es descrito por Arboleda-Quiñónez (1998) como estrategia de cohesión social y como escenario de solidaridad entre los negros del Pacífico migrantes en Cali entre los años sesenta y ochenta del siglo $\mathrm{XX}$. Si bien estas expresiones son símbolos de unidad entre las poblaciones negras que habitan en los grandes centros urbanos donde sufren el racismo cotidiano, su idea original se asocia con una estrategia de tipo pedagógico. "Su gente de uno" sugiere: "tenemos identidad", "somos una cultura", "tenemos derechos", "Somos Pacífico", por lo tanto, estos símbolos corresponden al ámbito de la escuela y se constituyen en estrategia de formación de la subjetividad colectiva afropacífica, afrocolombiana o afrodiaspórica.

Lo mismo ocurre con "cultura negra" y "negritud", expresiones utilizadas por Manuel Zapata-Olivella (1990), Amir Smith Córdoba (1980) y Jesús Lácides Mosquera (1975), quienes buscan afanosamente un punto de articulación política de las comunidades. A la cultura negra la constituyen saberes, tradiciones y aportes a la nacionalidad, pero también una posibilidad de unidad de los negros que, además, abre caminos para la construcción de identidad nacional. Desde este punto de vista, “cultura negra" y "negritud" son expresiones que funcionan como esponjas para la congregación del negro en el ámbito nacional y mundial. 
La sugerencia de los autores radica en que, además de trabajar estos conceptos, desde sus contenidos académicos, históricos y epistemológicos, se apropiasen también en términos de construcción política, al mantenerlos como elementos de unificación del negro y como competencia de la escuela. Esta es la explicación que tienen los Seminarios para Formación del Personal Docente en Cultura Negra, que dirigió Amir Smith Córdoba en Bogotá en los años 1978 y 1979.

Transformados los poderes de la escuela en la forma como se lo ha descrito, los elementos cohesionadores de la población negra, que han sugerido los pensadores como estrategia pedagógica, tienen un campo para su realización plena: el ámbito escolar. De esta manera, la escuela oficial que se instaló en las comunidades para promover el discurso académico occidental empieza su proceso de trasformación para llegar a un escenario deseado que los maestros de La Playa llamaron la Escuela Afrocolombiana.

\section{Cultura negra e intelectualidad}

Al pasar a otro plano de esta reflexión, el pensamiento educativo afrocolombiano del siglo XX puede analizarse desde otras perspectivas políticas. Por un lado, como ya se ha dicho, Rogerio Velásquez y Manuel Zapata-Olivella anuncian, desde sus textos, la necesidad de intelectuales negros que asumieran la representación de sus comunidades, ya sea desde la función docente o desde las acciones del liderazgo organizativo. Con estas ideas, los dos pensadores han puesto quizás el punto más alto que, en términos políticos, pudiera ser resultante de los procesos educativos y organizativos del pueblo negro colombiano. La intelectualidad, desde esta óptica, se constituye en el fin último del proyecto educativo afrocolombiano, pero no se agota solo en la capacidad intelectual del maestro que construye los símbolos aglutinadores; su labor empieza a producir verdaderos frutos cuando, desde el seno de las comunidades con las que trabaja, emergen intelectualidades comprometidas con las necesidades y adversidades de sus pueblos. La función del maestro intelectual termina por crear una nueva intelectualidad que, al dar continuidad a los procesos de problematización de la historicidad propia, garantizarían al mismo tiempo los escenarios de negociación en la compleja relación de los pueblos negros con las esferas dominantes del país.

Los perfiles de esa intelectualidad afro, de acuerdo con los autores en mención, se ubican en el conocimiento de la historia del negro, como lo ha mostrado Máximo, en Chambacú, corral de negros (1990a), pero también en la actitud beligerante del maestro Olivares, en la novela Tierra mojada de Zapata-Olivella (1972). El respeto por las decisiones colectivas, su sentido de pertenencia a la negritud, el arraigo en la sabiduría ancestral de su pueblo, la capacidad de establecer rupturas epistemo- 
lógicas y, en pocas palabras, mostrar su carácter insumiso, son los otros elementos que desarrollan una posición crítica fuerte y un perfil político de la intelectualidad afrocolombiana. Con estos rasgos, la intelectualidad es principio y final del proyecto educativo, donde las comunidades negras asegurarán el respeto a su dignidad y podrán proponerle alternativas de convivencia al país.

Por otra parte, en el discurso educativo afrocolombiano está presente la idea de pensamiento de región, que comporta un doble sentido: por un lado, la obra de Miguel A. Caicedo-Mena, Jesús Lácides Mosquera y Rogerio Velásquez inducen a pensar en el Chocó y en el Pacífico en general como una construcción política y administrativamente autónoma. Sus respectivos discursos, al ahondar sobre la situación de marginalidad y exclusión en que viven estas poblaciones, no solamente se leen como una sugerencia a la escuela respecto a la definición de contenidos académicos que ayudasen para la comprensión histórica de estas condiciones absurdas de vida, sino también como la posibilidad de construir "región" que, en términos territoriales, políticos y culturales, debería adquirir la categoría de comunidad autónoma. El pensamiento de Región Pacífica es un viejo anhelo de sus habitantes, insinuado por los intelectuales, discutido por los líderes de las organizaciones y convertido en objeto de estudio para la escuela. La noción de autonomía territorial en la región del Pacífico es parte del discurso político de los eventos y procesos educativos agenciados por el movimiento social afrocolombiano.

El segundo sentido, que se debe abordar en esta reflexión, establece que el pensamiento de región alude también a los discursos radicales de reivindicación de derechos, donde los pensadores y las organizaciones territoriales, al superar las dinámicas locales, se han puesto, en términos políticos y filosóficos, en el límite del pensamiento occidental a partir de la insumisión epistémica. De este modo, se crea un pensamiento de región al estilo del pensamiento fronterizo (Mignolo, 2002), ya que los discursos educativos y los escritos culturales y políticos de los intelectuales negros del Pacífico y de Colombia se han desarrollado al margen del canon literario, social e institucional.

Así mismo, como pensamiento que se mueve en la exterioridad del discurso político y académico de la universidad colombiana, el pensamiento de región afrocolombiano es eludido como campo epistémico. Esta es la razón que fundamenta la vertiente política radical de la intelectualidad afrocolombiana que, de acuerdo con las sugerencias de Jesús Lácides Mosquera, Amir Smith Córdoba, Manuel González y Obirne Carabalí3 , debe ser un propósito de la Escuela que ha transformado

3. Los dos últimos personajes son maestros que lideran procesos de etnoeducación afrocolombiana en Buenaventura y Jamundí, respectivamente. 
sus poderes en favor de la cultura y las tradiciones en los territorios con población mayoritariamente negra.

La cultura de la que se habla aquí no se refiere solo a los asuntos de la producción material, las danzas y los ritmos musicales folclorizados; no se trata solamente de tocar el tambor y bailar, como lo ha recalcado Amir Smith Córdoba (1980: 116): "es cierto que el negro baila y muy bien, pero en el mejor de los casos lo que queremos es no quedarnos bailando". Este autor advierte, también, que detrás de la noción vulgarizada de la danza y el tambor se ocultan la cultura y los rasgos de la identidad del negro. Entonces, se trata de que, en la música y el ritmo, el negro pudiera descubrir el arte vernacular y los valores propios de su esencia (1980: 71). En consecuencia, la cultura, y específicamente la cultura negra, además de una construcción política, igual que el concepto de negritud, adquieren un estatuto espiritual y filosófico, que lamentablemente no se ha considerado como tal por la despersonalización del negro causada por la cultura occidental.

El maestro Manuel Zapata-Olivella (citado en el I Foro Nacional de Etnoeducación Afrocolombiana, Ministerio de Educación, 2004) sostenía que las contribuciones culturales de las comunidades negras no tienen que ver solamente con las manifestaciones de tipo material, como el tambor, la alimentación, entre otros temas; por el contrario, los grandes aportes de la cultura negra tienen que ver con las primeras manifestaciones de convivencia, el arte, la religión, la filosofía, etc.

Amir Smith Córdoba y Zapata-Olivella no solo desfolclorizan la cultura negra, sino que, además, la ponen en el sitio que les corresponde a las grandes y primigenias realizaciones humanas. Esta contribución, en materia educativa, alcanza una altísima importancia en la medida en que la enseñanza de la cultura negra, en el sentido que estos autores le han otorgado, debe suscitar trasformaciones definitivas en la base social y política de los afrocolombianos. En últimas, y como deducción de lo que han planteado estos pensadores, la cultura negra, en términos de cultura propia, se ha construido y se sigue construyendo por fuera de la casa del amo. En condición de esclavizado, al negro no le quedaba más que reproducir las costumbres del colonizador, mientras que aquellos que lograron el escape a otros mundos, al mundo del cimarronaje y la libertad, pudieron construir una cultura centrada fundamentalmente en un pensamiento desesclavizador. Desde este punto de vista, la cultura propia es aquella que surge por fuera de todo sistema de sujeción y puede viajar mentalmente como pensamiento insumiso, palenquero, diaspórico, cimarrón, etc., de generación en generación. Desde esta óptica, por fuera de la casa del amo es un concepto que no está determinado en perspectiva geográfica y biofísica, es más bien un asunto de mentalidad y actitud beligerante y crítica que funciona al interior mismo de la lógica de la modernidad euronorteamericana con diversas formas de 
representación y de respuesta a las políticas de dominación. En este sentido, el pensamiento educativo afrocolombiano como reproductor de la cultura propia es un discurso que al construirse y socializarse al margen y en contravía de la institucionalidad se comprende como una forma "otra" de pensar desde la exterioridad. En consecuencia, la educación para la liberación solo puede concebirse como reproducción de la cultura propia; así lo entendieron las experiencias educativas del movimiento social, al asumir la cultura negra como "lo propio", "lo nuestro". La cultura propia, en términos de pensamiento desesclavizador, corresponde a aquello que se debe reproducir en la escuela a contrapelo de la cultura del dominador, presente en el proyecto estandarizado de educación estatal.

El reclamo sobre la invisibilización de los aportes del negro en el relato de constitución de nación ya no parece tener mucho sentido, planteado desde la visión epistémica afrodiaspórica. Siendo hegemónico y justificador de la primacía blanca, el relato de nación, en la historiografía oficial, de ninguna manera podría incluir el aporte negro. Por lo tanto, la reiterada reclamación de líderes del movimiento social afrocolombiano debe traducirse más bien en un proyecto de reconstrucción de la memoria epistémica afrodiaspórica, con miras a constituir un nuevo relato, de manera que este pudiera dialogar con otros modos de pensar, incluida la perspectiva dominante de la nación colombiana.

Esta, por supuesto, no será una labor asignada a quienes representan, de alguna manera, la "tradición académica colombiana" y latinoamericana; debe ser, ante todo, un propósito inaplazable de pensadores y pensadoras negras que trabajan desde los circuitos periféricos y exteriores al macrorrelato nacional y que tendrán como quehacer urgente dar continuidad y movilidad al pensamiento de los precursores. El pensamiento afro insumiso y descolonizador es beligerante con el sistema esclavista del capitalismo contemporáneo y con todos los marcadores de racismo que se derivan de él, pero es solidario, benigno y ético con las otras sociedades y culturas avasalladas. Para una comprensión más situada sobre este planteamiento, habría que retomar aquí la concepción amplia y profunda del proletariado en el discurso de Diego Luis Córdoba (1945, como se cita en Arboleda, 2011) y la visión del mestizaje radical en la obra de Manuel Zapata-Olivella (1990a).

Desde otro ángulo, se puede afirmar la existencia de dos aspectos que gravitan en el pensamiento educativo afrocolombiano: 1) la lucha por la tierra, que se puede verificar en las dos novelas de Zapata-Olivella (Chambacú, corral de negros y Tierra mojada), pero también en las experiencias educativas comunitarias del norte del Cauca, sur del Valle, Buenaventura, y en el estudio socioeconómico del Atrato medio, de Rogerio Velásquez; 2) la lucha por la inclusión de la cultura negra en los planes de estudio oficiales; en este punto, también es pertinente mencionar el aporte de 
Zapata-Olivella y Amir Smith Córdoba, además de las experiencias educativas de San Basilio de Palenque y La Playa.

En el primer punto, la sugerencia de los autores señala que el territorio, donde sucede la vida de las comunidades, es también el escenario donde debe suceder un proyecto educativo endógeno, que pudiera sustentar las bases espirituales, sociales y políticas de estos pueblos. Dicho proyecto, caracterizado principalmente por su papel en el afianzamiento de la relación hombre-naturaleza, por la reafirmación de prácticas ancestrales de vida y por el principio de la solidaridad, se constituye en bastión para la autonomía territorial y para la defensa de una forma específica de existir.

El segundo aspecto, en cambio, se refiere al cordón umbilical que une a los pueblos negros con el resto de las sociedades. La inclusión de la cultura negra en la educación formal no es realmente una solicitud, sino una exigencia basada en la necesidad y en el derecho de todos los colombianos y todos los hombres y mujeres del planeta a conocer África como cuna de la humanidad. En este sentido, más que una necesidad del negro, los estudios de la cultura negra son un asunto vital que compromete la identidad humana.

Estos son, de nuevo, los dos grandes componentes de la educación afrocolombiana: una educación propia hacia adentro de los territorios y una propuesta para el conocimiento de la cultura negra como patrimonio de todos los colombianos. La diferencia entre estas dos formas de entender el proceso educativo afro es lo que no parece entenderse en los textos de Juan de Dios Mosquera (1999).

El discurso de Mosquera (1999) prefiere la idea de la educación como escenario de reconciliación nacional o, lo que es lo mismo, la construcción de una ciudadanía común, donde no existiera el racismo ni la discriminación. Este ideal de democracia está contenido, desde 1820, en la primera política pública de educación en el país (Jaramillo-Uribe, 1989). La educación, en este proyecto, tiene como propósito principal la construcción de una sociedad democrática para una ciudadanía plena. No obstante, es imposible olvidar que la pequeña burguesía que derrotó a los españoles, con la ayuda de negros e indígenas, dio continuidad, en la República, a los rasgos fundamentales del colonialismo que supuestamente habían combatido; además, mantuvo la misma estructura social, política y económica y el régimen esclavista, lo cual indica, al parafrasear a Rogerio Velásquez (2010), que a estos colonizadores criollos ni a su descendencia les interesaba la educación para negros. Con discusiones y debates muy fuertes al interior de las elites liberales y conservadoras durante la segunda mitad del siglo XIX, la educación colombiana se constituye en escenario de disputa partidista, debate que se prolonga hasta mediados del siglo XX.

Por directivas de los emporios económicos mundiales, que han considerado estratégica la apertura a la diversidad en las constituciones políticas en América Latina 
al finalizar la década del ochenta, pero también por la acción reivindicativa de los movimientos sociales en la misma época, la aristocracia blanca colombiana se ha visto obligada a flexibilizar algunas políticas y, en el campo educativo, abrió espacios de debates al final del siglo XX bajo la sombrilla multicultural de la inclusión social; en estos escenarios, negros, indígenas y otros grupos supuestamente subalternos pudieron expresar sus posiciones. No significa ello que el proyecto hegemónico de país hubiera desaparecido; por el contrario, lo que ha ocurrido es un afianzamiento del multiculturalismo de Estado y, más concretamente, de la democracia liberal, empeñada en un reconocimiento de las etnias, pero bajo la condición de mantener intacto el racismo estructural y colonial. La apertura para incluir la diversidad cultural en las constituciones, antes que apostarle a la democratización de las naciones de América, se asocia más bien con un ejercicio de control pacífico de la población en países "periféricos".

Con estas consideraciones, a las elites colombianas no parece interesarles mucho una reconciliación nacional por la vía de la educación. El discurso de Juan de Dios Mosquera (1999) cae en esta trampa; los otros autores que se han estudiado aquí, así como las experiencias educativas propias, tienen claridad sobre el conflicto histórico y político del país y, por esa razón, se comprometen en un ejercicio de comprensión crítica de la realidad dirigido a la concreción de una subjetividad colectiva afro capaz de confrontar no solamente el estratégico y falso discurso oficial, sino también sus formas específicas de afectar el lenguaje y la producción de cultura en las comunidades.

En el pensamiento educativo afrocolombiano sigue vigente la idea de que la educación propia no debe reducirse solamente a la recuperación y registro de las tradiciones culturales folclorizadas; debe comprender, ante todo, el sentido crítico político que implica un aprendizaje del orgullo de ser negro y, además, debe ocuparse de la orientación de un pensamiento insumiso que pudiera enfrentar las reglas oficiales establecidas y los marcadores de racismo del sistema colonial contemporáneo.

Ahora bien, los eventos nacionales celebrados en Bogotá (1986), Quibdó (1991), Tumaco (1992), Cartagena (1993), Guapi (1994), así como las sesiones de la Comisión Pedagógica Nacional de las Comunidades Negras, no solo representan avances en la construcción del pensamiento educativo afrocolombiano, sino que también, de alguna manera, se constituyen en el lugar histórico de las transferencias de los legados políticos e ideológicos de los intelectuales a las organizaciones y comunidades negras de base. En efecto, estos grandes eventos nacionales, en los años noventa y siguientes, suscitaron un número indeterminado de reuniones comunitarias, talleres rurales, foros locales, encuentro de mayores y sabedores, que consolidaron el discurso cultural y educativo en los territorios de las comunidades negras. 
Mary Lucía Hurtado (comunicación personal, o8.02.2015) aduce que, en este relevo, se presenta un cambio de metodología; es decir, mientras que en los años setenta y ochenta los intelectuales tenían la primacía del discurso educativo, se tomaban todos los escenarios de debate y representaban una cierta autoridad incuestionable, las comunidades negras, organizadas a partir del Artículo transitorio 55 de la Constitución Política, específicamente gente de los ríos del Pacífico, líderes campesinos sin preparación académica, inician debates y reflexiones sobre la base de una categoría nueva: construcción colectiva. Aquí, los intelectuales cambian de nombre; ahora son líderes comunitarios y maestros rurales que desarrollan reflexiones profundas sobre historia, territorio y educación, y lo hacen en escenarios propios al interior de los pueblos, de ríos, selvas y manglar. De estas reflexiones comunitarias, en materia educativa, surgen elementos que coinciden con los postulados del evento del Quinto EPA (Diócesis de Quibdó, 1991), que constituyen las bases para el articulado del Capítulo VI de la Ley 70 de 1993 y, en los años siguientes, contribuyen con sus aportes y fortalecen el discurso educativo afrocolombiano.

Sin embargo, las experiencias educativas propias que, en los años noventa, se consideran un resultado del proceso de relevo entre los intelectuales y las comunidades sufren giros lingüísticos inadecuados, que desdibujan las visiones iniciales de estos proyectos. Desaparecen la cultura negra y el etnónimo negro, con el que los intelectuales designaban a la gente con ancestro africano, y se recurre al uso de los términos afrocolombianidad y etnoeducación. Como apreciación personal, el lugar preciso donde se produce este cambio de lenguaje en el pensamiento educativo afrocolombiano tiene que ver con los discursos de Juan de Dios Mosquera (1999), muy seguramente influenciados por la corriente afroamericanista en la lucha por los derechos civiles de los negros en Norteamérica y por el lenguaje académico e institucional colombiano. Mosquera (1999) va a insistir, a partir del noventa, en que no se debe utilizar la palabra negro, por considerarla peyorativa, con lo cual se opone a la resignificación del término que, de algún modo, los intelectuales anteriores a él ya habían consensuado; pero quizás el mayor problema que se deriva de este giro lingüístico eufemístico se asocia con la pérdida de la radicalidad política que implicaba la utilización de las expresiones “negro" y “cultura negra”. También, se podría decir que el multiculturalismo institucional que arranca con fuerza en la década del noventa desactiva el discurso racial en términos de proyecto político de los pueblos. Se impone a cambio una suerte de racismo multicultural que a partir de los años noventa incursiona en el juego simultáneo y perverso de reconocimiento y negación.

Mientras los intelectuales defendían los derechos de la raza negra y se oponían a la racialización como estrategia colonial despectiva que comporta jerarquización entre los seres humanos, los nuevos discursos de la educación afrodiaspórica en Colombia 
mimetizan pedagógicamente el contenido político de este pensamiento. La afrocolombianidad, en cuanto relato folclorizado de la cultura negra, empieza a constituirse en lenguaje oficial y funciona como un velo sobre los verdaderos problemas de los negros, que la educación, en perspectiva propia, tiene el compromiso de visibilizar.

\section{Conclusiones}

La inclusión de la cultura negra en el proyecto educativo estatal fue una exigencia de varios pensadores negros colombianos en el siglo XX. Esta exigencia apuntaba a una transformación de la estructura del poder educativo estatal y no tanto a una cátedra de aplicación instrumental, como viene sucediendo en los escasos ejemplos de instituciones educativas que aplican los estudios afrocolombianos; contrario a lo que se viene concibiendo, se trata de la vinculación de la diversidad ontológica y epistemológica de la sociedad colombiana, ya que toda cultura tiene derecho a un lugar en el sistema de enseñanza pública de su país. De este modo, la inclusión de la cultura negra en los pénsums académicos de los países de América representa un pensamiento de ruptura, pero también una propuesta para una nueva concepción de la educación y la posibilidad de una interculturalidad real y concreta.

Si bien este es un artículo sobre educación, no lo es de cualquier educación, sino de aquella que ha sido barruntada por el pensamiento de hombres y mujeres intelectuales, maestros y líderes comunitarios negros, que tomaron como bandera la exaltación de los valores de su raza y crearon un campo epistémico-educativo en contravía del hegemónico y andinocéntrico proyecto oficial de educación colombiano. Dicho campo epistémico es posible considerarlo como continuo en la línea del horizonte histórico del pensamiento crítico afrocolombiano.

En una sociedad como la colombiana, que conserva incólume la estructura racista del sistema colonial, los discursos educativos afrocolombianos del siglo XX dan cuenta de la emergencia de un fenómeno insurreccional frente a las concepciones de educación estatal; sin embargo, a este discurso no se le puede asignar la categoría de voces aisladas, sino, por el contrario, se lo debe reconocer en el marco del pensamiento político afrodiaspórico, esto es, la afirmación y defensa de la dignidad humana de los negros que el macrorrelato de los sectores dominantes y elitistas de la nación colombiana ha soslayado y negado. Desde luego, este pensamiento tiene conexiones inevitables con los movimientos intelectuales de la diáspora africana en el mundo, principalmente las negritudes, los congresos panafricanos, la lucha por los derechos civiles de los negros norteamericanos y además ha contado con la iluminación del pensamiento afrocaribeño destacándose las figuras de Fanon, Césaire, Damas, Rodney, Williams, Glissant, entre otros. 
El campo político afrodiaspórico en Colombia entraña como uno de sus bastiones claves el discurso educativo en términos de escenario, no solo para la reafirmación de la identidad negra, sino como posibilidad de encuentro con la diversidad cultural de la nación. Al respecto, se podría decir que tres son los grandes obstáculos que este discurso enfrentó desde los inicios del siglo XX hasta nuestros días. En primer lugar, los intelectuales negros (Manuel Zapata-Olivella, Rogerio Velásquez, Diego Luis Córdoba) cuestionaron al Estado por negar a los negros como sujetos de formación escolar. En efecto, como resultado de la reforma educativa de 1903, donde el Estado asigna solo tres años para la primaria rural, el campesinado negro solo pudo asegurar un acceso muy precario cuando no inexistente a la educación básica. Este asunto enardece los ánimos de estos pensadores, especialmente el de Diego Luis Córdoba, que tiene que enfrentarse en solitario al Congreso de la República para garantizar dos instituciones de educación media para el Chocó a mediados de los años treinta. En segundo lugar, una vez instalada la educación oficial en los territorios negros, la acción intelectual de los pensadores se transforma en una crítica al proyecto civilizatorio del Estado. Si bien se requiere educación para las poblaciones negras, indígenas y mestizas, en las voces de Zapata-Olivella esa educación no debe confundir el concepto de cultura nacional, asignándolo a las tradiciones de la elite blanca. La cultura nacional está integrada por todas las culturas populares de las diferentes regiones del país. Sin duda, este cuestionamiento aparentemente sencillo es una crítica al racismo escolar y a la educación dominante y elitista del sistema oficial. En tercer lugar, en medio de estas consideraciones, los pensadores, especialmente Rogerio Velásquez, aspiran que los pueblos puedan desarrollar su propia educación. Aunque este concepto se encuentra también en Zapata-Olivella, es Velásquez quien desarrolla esta idea con más contenidos prácticos y sistemáticos.

Finalmente, en la crítica de los intelectuales negros al sistema público de educación se pueden percibir unas búsquedas concretas que aparecen en las novelas y ensayos de forma subrepticia, pero muy sugerente. Se podría afirmar por ejemplo que la lucha por la tierra o quizás por el control político de los territorios, la lucha incesante contra la sociedad clasista y racista, el interés del acenso social de los negros por la vía de la educación y la necesidad de demostrar capacidad para una discusión epistemológica y política con las altas esferas del país son, entre otras, grandes preocupaciones de la intelectualidad negra colombiana. 


\section{Referencias}

Arboleda-Quiñónez, Santiago (1998). Le dije que me esperara, Carmela no me esperó: el Pacífico en Cali. Cali: Universidad del Valle.

Caicedo-Mena, Miguel A. (2011). Sólidos pilares de la educación chocoana. Quibdó: Hebrón.

Castro-Gómez, Santiago (2010). La hybris del punto cero: ciencia, raza e ilustración en la Nueva Granada (1750-1816). Bogotá: Pontificia Universidad Javeriana.

Castro-Gómez, Santiago; Grosfoguel, Ramón (2007). El giro decolonial, teoría crítica y pensamiento heterárquico. Bogotá: Pontificia Universidad Javeriana/Instituto Pensar.

Chaves-Maldonado, María Eugenia (2009). La creación del "otro" colonial. Apuntes para un estudio de la diferencia en el proceso de la conquista americana y de la esclavización de los africanos. En Genealogías de la diferencia: tecnologías de la salvación y representación de los africanos esclavizados en Iberoamérica colonial (pp. 178-243). Bogotá: Pontificia Universidad Javeriana/Instituto Pensar/Abya-Yala.

Córdoba, Amir Smith (1980). Cultura negra y avasallamiento cultural. Bogotá: MAP.

Córdoba, Diego Luis (1934). Discurso pronunciado en la Cámara de Representantes el 4 de septiembre. Bogotá: Suplemento a los Anales de la Cámara de Representantes.

Diócesis de Quibdó (1991). Quinto Encuentro de Pastoral Afroamericana. Memoria y conclusiones. Recuperado de http://axe-cali.tripod.com/cepac/epa5.htm

Dussel, Enrique (1994). El encubrimiento del otro: hacia el origen del mito de la modernidad. Quito: Abya-Yala.

Fanon, Frantz (1983). Los condenados de la tierra. México: FCE.

Flórez-Bolívar, Francisco Javier (2009). Iluminados por la educación: los ilustrados afrodescendientes del Caribe colombiano a comienzos del siglo XX. Cuadernos de Literatura del Caribe e Hispanoamérica, 9, 35-58. Recuperado de http://investigaciones.uniatlantico.edu. co/revistas/index.php/cuadernos_literatura/article/view/542/320

Foucault, Michel (2010). El orden del discurso (2. ${ }^{\circ}$ ed.). Barcelona: Tusquets.

Freire, Paulo (1967). La educación como práctica de la libertad. Río de Janeiro: Paz e Terra.

García-Rincón, Jorge Enrique (2011). Diáspora africana en Colombia: etnoeducación, racionalidades y cultura. Buga: Universidad del Valle.

García-Rincón, Jorge Enrique (2014). Racismoy pensamiento latinoamericano. La subalternización de la diáspora africana en América. Estudios Latinoamericanos, 34-35, 51-62. Recuperado de https://revistas.udenar.edu.co/index.php/rceilat/article/view/3761/4454 
García-Rincón, Jorge Enrique (2016). Por fuera de la casa del amo: insumisión epistémica o cimarronismo intelectual en el pensamiento educativo afrocolombiano siglo XX. Pasto: Universidad de Nariño.

Grosfoguel, Ramón (2012). El concepto de racismo en Michel Foucault y Frantz Fanon: ¿teorizar desde la zona del ser o desde la zona del no-ser? Tabula Rasa, 16, 79-102. Recuperado de https://www.redalyc.org/pdf/396/39624572006.pdf

Herrera-Ángel, Martha (2010). El arrochelamiento: nominar para criminalizar. El Taller de la Historia, 2, 11-46. https://oi.org/10.32997/2382-4794-vol.2-num.2-2010-653

Jaramillo-Uribe, Jaime (1989). El proceso de la educación en la República (1830-1886). En Nueva historia de Colombia, tomo 2 (pp. 223-250), dirigido por Álvaro Tirado-Mejía. Bogotá: Planeta.

Lácides-Mosquera, Jesús (1975). El poder de la definición del negro. Ibagué: Universidad del Tolima.

Maldonado-Torres, Nelson (2007). Sobre la colonialidad del ser: contribuciones al desarrollo de un concepto. En El giro decolonial: reflexiones para una diversidad epistémica más allá del capitalismo global, editado por Santiago Castro-Gómez y Ramón Grosfoguel. Bogotá: Pontificia Universidad Javeriana/Instituto Pensar/Universidad Central/Siglo del Hombre.

Mignolo, Walter (2002). Historias locales/diseños globales: colonialidad, conocimientos subalternos $y$ pensamiento fronterizo. Madrid: Akal.

Mosquera, Jesús Lácides (1975). Mosquera, Juan de Dios (1999). La etnoeducación afrocolombiana: guía para docentes, líderes y comunidades educativas. Bogotá: Docentes Editores.

Nietzsche, Friedrich (200o [1981]). La voluntad de poder. Madrid: Edaf.

República de Colombia, Ministerio de Educación Nacional (2004). Reconocimiento al maestro Manuel Zapata Olivella. En I Foro Nacional de Etnoeducación Afrocolombiana (pp. 133-134). Bogotá: Ministerio de Educación Nacional. Recuperado de http://www.mineducacion.gov. co/1759/articles-85375_archivo_pdf.pdf

Velásquez, Rogerio (2010). Apuntes socioeconómicos del Atrato medio. En Ensayos Escogidos (pp. 133-219). Bogotá: Ministerio de Cultura.

Zapata-Olivella, Manuel (1972). Tierra mojada. Medellín: Bedout.

Zapata-Olivella, Manuel (1988). Discurso de apertura al Congreso de la Cultura Negra. Nueva era para la identidad de América. En Memorias del Primer Congreso de la Cultura Negra de las Américas (pp. 19-21). Bogotá: Unesco/Fundación Colombiana de Investigaciones Folclóricas. 
Zapata-Olivella, Manuel (1990a). ¡Levántate, mulato!: por mi raza hablará el espíritu. Bogotá: Rei-Andes.

Zapata-Olivella, Manuel (1990b). Chambacú, corral de negros. Bogotá: Rei-Andes.

Zapata-Olivella, Manuel (1992). Changó, el gran putas. Bogotá: Rei-Andes. 